\title{
CORPO, EDUCAÇÃO INTERCULTURAL E CIDADANIA: O OUTRO COMO SUJEITO DAS RELAÇÕES EDUCATIVAS DE ENSINO, PESQUISA E EXTENSÃO
}

\author{
Nadir Esperança Azibeiro
}

\section{INTRODUÇÃO}

Que o leitor não espere encontrar aqui um quadro acabado. O que ele vai ler, incompleto, recheado de pontos de interrogação, não passa de um esboço[1].

Embora destaque neste início de século, a maior parte das obras sobre o corpo constituem-se sob enfoques disciplinares da medicina, educação física, sexualidade ou moda. Raras vezes há uma associação entre corpo e educação, ou corpo e cidadania. Até por isso, optamos por tomar esse caminho. Com Sennet, colocamo-nos o desafio de perceber, a partir do entendimento da experiência corporal do povo (1997:15), como as marcas da história se inscrevem nas próprias posturas corporais dos membros da comunidade. Com Bhabha, começamos a nos colocar na perspectiva de buscar entender o inter, não como o lugar exótico da diversidade, mas na inscrição e articulação do hibridismo da cultura, nos colocando nesse entre-lugar, sobre o fio cortante da tradução e da negociação (1998, p. 69).

A comunidade à qual nos referimos é a comunidade Nova Esperança, situada em Florianópolis, na região do Bairro Monte Cristo, no Continente. Essa comunidade se originou de uma ocupação organizada a partir da participação no Movimento Sem Teto. Enquanto movimento, e nos primeiros momentos da ocupação, a comunidade parecia amalgamar e igualar seus participantes. Eram os mesmos objetivos que se destacavam: ter um teto, adquirir a dignidade de cidadão, conquistando o seu espaço na cidade. Para quem observava de fora, a própria participação no mutirão e a mudança para as casas já se refletia em seus corpos, percebendo-se e expressando-se não mais como pedintes, sentindo-se como que miraculosamente, pela posse do teto, transformados em cidadãos. Com o passar dos anos, porém, as diferenças foram aparecendo, manifestando-se não raro como cisões, como fraturas. As descontinuidades da história de cada um - e da comunidade - foram se tornando explícitas, gritantes. Ao mesmo tempo, foram se dando conta de que ter um teto era muito, mas não garantia sua participação cidadã em todos os espaços da cidade, menos ainda nas decisões de seu destino.

Foi assim que encontramos a comunidade quando iniciamos a pesquisa que originou este ensaio. Percorremos, muitas vezes juntas, muitas vezes cada uma por si, mergulhada ou afogada em suas próprias questões e suas próprias tarefas, 
as trilhas deste labirinto. Buscamos transpor fronteiras disciplinares, falar do corpo não para tratar de saúde, beleza, sexualidade, moda, educação física, mas para tratar de educação e cidadania. Escancaramos para nós mesmas e para quant@ @ ${ }^{[2]}$ tiverem acesso a este texto que todo projeto de pesquisa coloca, explícita ou implicitamente, uma questão inicial: a concepção de conhecimento - e de realidade - a perspectiva de análise na qual se coloca cada pesquisador@. Descobrimos que em educação - como nas ciências humanas e sociais, em geral, essa questão é particularmente crucial: que papel se atribui à pesquisa e @ pesquisador@? O conhecimento é algo dado, que a pesquisa tem a função de descobrir? Ou é uma relação, continuamente reelaborada: reelaboração para a qual a pesquisa contribui, desmontando as relações de saber-poder já postas, as políticas de verdade vigentes?

\section{AS TRILHAS DO LABIRINTO}

Sempre que se produz um novo conhecimento também se inventa um novo e peculiar caminho. Quando olhamos para trás é que nos damos conta disso.[3]

Retomo mais uma vez o caminho percorrido. As questões da integralidade da educação - e da formação de educador@s - são preocupação constante e tema de pesquisa dos últimos dez anos. Assim também o trabalho com movimentos sociais e comunidades de periferia - que já vem de mais longe. Quando me deparei com casos de estagiári@s de licenciaturas e alun@s da Pedagogia que tinham medo de ir para escolas de periferia (e - o que é pior: em algumas situações, também @s professor@s!) percebi o quanto essas questões têm a ver e têm a contribuir com a formulação de referenciais e elaboração de subsídios para munir educador@s - docentes e não docentes - que vão atuar na educação pública.

Tenho claro que trazer a público essas questões - e a reflexão sobre elas - não garante qualquer melhoria nos processos de formação de educador@s, já que hoje acredito, como Costa, que "não há qualquer garantia no conhecimento; ele é sempre mais uma possibilidade e, sobretudo, uma aventura" (1995, p.109). Mas, justamente porque é possibilidade, vale a pena tentar. Ao lado dessa certeza coexiste uma outra, nascida, também, da reflexão da experiência: trazer para a formação de educador@s os conhecimentos produzidos a partir da relação de respeito e troca com as comunidades de periferia e, mais ainda, oportunizar @s futur@s educador@s a vivência dessas relações, pode mudar qualitativamente seu processo de formação, possibilitando a incorporação de mecanismos de tradução e negociação (Bhabha, 1998, p. 69).

O contato intencional e respeitoso com o outro - percebido como diferente, mas nem por isso valorado como inferior ou superior - que é próprio da abordagem intercultural, o reconhecimento do hibridismo, do entre-lugar onde nos movemos e a partir do qual falamos, possibilita relações recíprocas de aprendizado, ampliando os horizontes, ou as teias de significados, tanto do saber popular, quanto da academia. 
Quanto à questão da pesquisa, hoje entendo, como Corazza, que "o problema de pesquisa não é descoberto, mas engendrado. Ele nasce(...)do desassossego em face das verdades tramadas, e onde nos tramaram" (1996, p.119). Praticando, principalmente a partir de minha dissertação de mestrado, uma pesquisa que definia como transdisciplinar, deixei que Rodrigues questionasse essa nomenclatura ao afirmar que a "indisciplinaridade" - e não a inter, pluri, multi, ou mesmo transdisciplinaridade - deve ser "o ensinamento maior que se deve usufruir de diálogos(...)e mesmo de enfrentamentos entre disciplinas diversas: irreverência contra a propriedade privada de campos teóricos e empíricos; insolência contra a canonização de métodos" (1999, p.12).

Por isso nenhuma metodologia pode ser estabelecida a priori. É sempre um caminho que vai sendo aberto à medida que vai sendo trilhado (Antonio Machado) ${ }^{[4]}$. Essa idéia já estava presente quando da elaboração deste projeto de pesquisa. Mas naquele momento ainda era muito forte a conviç̧ão de que tod@s - pesquisador@s e comunidade - estariam envolvid@s em todas as decisões e em todos os momentos do processo: isso garantiria a experiência de cidadania!

Hoje sei, também, que "uma relação dialógica não é, necessariamente, uma relação de igualdade, nem garantia de participação democrática" (Costa, 1995, p. 133). A participação no movimento, ou em projetos de educação popular não traz necessariamente como conseqüência a tomada de consciência ou a emancipação. Se assim fosse não teríamos histórias tão frontalmente contraditórias como, por exemplo, a do Cláudio e a da Leda ${ }^{[5]}$. O que está sendo analisado sugere, no próprio percurso, um método de trabalho. Esse conceito foucaultiano está profundamente presente na idéia da descrição densa de Geertz (1989, p.15ss): os fatos falam, a seqüência dos acontecimentos é que vai abrindo possibilidades, definindo a metodologia, orientando os rumos do trabalho de pesquisa, como de suas articulações com o ensino e a extensão[6]. Este, por sua vez, vai dando visibilidade aos sujeitos - pesquisador@s e pesquisad@s - ou melhor, possibilitando outros processos de subjetivação.

Não somos mais@s mesm@s - envolvid@s num projeto de pesquisa - como também não são mais @s mesm@s aquel@s que pesquisamos. Ao mesmo tempo, o envolvimento de tod@s - pesquisad@s e pesquisador@s - no processo, não é o mesmo: cada um participa de acordo com seus interesses, possibilidades, perspectivas. Foi à medida que entendemos e respeitamos isso que conseguimos criar nosso novo e peculiar caminho.

\section{DESENROLANDO O PRIMEIRO CARRETEL...}

Toda compreensão é temporal, existencial, histórica. Não se trata de um processo mental, através do qual dominamos objetos, mas de um processo ontológico[7] 
A comunidade não é um todo homogêneo, uniforme, coerente. Ela se nos apresenta múltipla, não só pelas várias leituras possíveis, mas também por seu dinamismo e plasticidade. O que é hoje, pode não ser mais amanhã. E pelos mais diversos motivos. Há rupturas bruscas, violentas, que causam transformações em cadeia (efeito dominó). Há também quebras mais sutis, quase imperceptíveis, cujos desdobramentos só vão ser percebidos com o passar do tempo.

Quando convidamos@s morador@s para, junt@s, revermos o vídeo da inauguração, os dez anos decorridos estavam estampados em primeiro lugar nos corpos: das crianças, que se transformaram em jovens, dos pais e das mães, agora dez anos mais velhos. Mas dentre todos alguns corpos se destacavam pela ausência: aqueles que, tendo participado da ocupação e do mutirão, já não estão mais entre eles - pela separação do casal; porque já morreram; por terem trocado ou vendido suas casas.

Uma dessas figuras é dona Alice. Destaco-a como uma daquelas que epifanizam a história da comunidade, não apenas pela importância de sua presença, nestes dez anos, mas - talvez - principalmente, agora, por sua ausência - porque aquel@s que entrarem em contato com a comunidade de agora em diante talvez não tenham a oportunidade de conhecê-la.

Dona Alice é da região serrana, descendente de migrantes italianos, radicada em Florianópolis desde meados dos anos oitenta. Falante, ereta, muitos moradores da comunidade, assessorias, padres, políticos, consideravam-na quase que portavoz, representante por excelência da Nova Esperança. Foi professora primária no interior - por indicação e nomeação de políticos - o que talhou para sempre seu perfil de devedora de um favor que Ihe garantiu a sobrevivência, bem como a de sua família. Quando veio para Florianópolis, mais uma vez por benefício político, conseguiu ser transferida para o colégio Ivo Silveira, como servente.

À época da preparação da ocupação, morava de aluguel e estava ameaçada de despejo. Convidada por uma vizinha, começou a participar das reuniões do movimento sem teto, sendo integrada ao grupo que se preparava para a ocupação. Católica praticante, era bastante considerada pelos padres e por todo o pessoal da igreja. Pelas imagens mostradas pelo vídeo da inauguração, percebese que também era considerada pelas autoridades do município, pois foi ela quem recebeu, simbolicamente, em nome de toda a comunidade, a chave da casa, das mãos do secretário do continente, que representava o poder público municipal.

Foi várias vezes coordenadora da comunidade. Quando iniciamos esta pesquisa, a coordenadora era sua filha, Lenir, mas quem decidia o que podia ou não, o que devia ser feito ou não, era dona Alice. A comunidade estava, então, profundamente dividida entre os que a apoiavam - ou ao menos tinham respeito por ela - quase medo - a aqueles que achavam que as coisas não podiam continuar assim, só uma pessoa mandando.

As controvérsias em torno de sua figura chegaram ao auge durante a campanha política municipal de 2000 , quando um candidato a vereador - licenciado do cargo de fiscal por causa da candidatura - com a promessa de melhorar a casa (sede) 
da comunidade, construindo outro pavimento, teve a permissão de dona Alice para destelhar a casa e levar as telhas para outro local, o que fez da antiga casa comunitária primeiro um depósito de lixo, depois, um abrigo para encontros noturnos e consumo de drogas.

No início do ano de 2001, finalmente um grupo tomou coragem de se articular para compor uma nova chapa para a diretoria da associação. Uma semana antes da eleição, um acontecimento trágico e doloroso acabou acelerando e, até, facilitando (sic) o processo: um dos filhos da dona Alice matou o enteado, de 22 anos - Robson. A tragédia, embora poucos queiram falar sobre ela, acabou por se tornar um daqueles acontecimentos que, por um efeito dominó, muda repentinamente vários aspectos da configuração e do jogo de forças na comunidade.

\section{FIGURAS DA RUA DOS FUNDOS QUE EPIFANIZAM A COMUNIDADE}

Até em seus aspectos mais "privados" esse corpo só é construído para ser visto[8]

Um dos aspectos que mudou na comunidade é a participação e o protagonismo assumido por algumas das figuras da rua dos fundos, às quais anteriormente nunca tínhamos prestado muita atenção.

A rua dos fundos dá para o barranco dos prédios do Promorar ${ }^{[9]}$. Numa das casas do meio da rua mora a Ana. Muito magra, nunca aparece sem estar impecavelmente arrumada, assumindo sua negritude com cabelos cuidadosamente trançados e adornados. O mesmo acontece com suas filhas, duas negras belíssimas. Participando do grupo da cerâmica, tornou-se muito próxima de nós. Foi por essa proximidade que conhecemos uma outra Ana. Folheávamos álbuns de fotografia - muitos, para os padrões comuns na comunidade, onde algumas pessoas nos pediram, quando fotografávamos as oficinas, para fazer uma foto das crianças, ou uma foto da família inteira, porque não tinham nenhuma. Reparamos que havia muitas fotos cortadas - ou recortadas. As filhas comentaram: "é a mãe que se corta, ela não gosta de aparecer em foto".

Perguntando para Ana o porquê, primeiro ela disse que era porque não estava bem. Até bem pouco tempo atrás, antes de aparecer uma úlcera gástrica, ela bebia, com uma certa freqüência, "quase até cair". Depois, meio entre dentes, murmurou: "não quero que ninguém fique com a minha cara!" Diante da nossa surpresa explicou que quando ela era criança, a madrinha tirava muitas fotos dela. Depois, um dia, se desentenderam, e a madrinha levou uma foto dela para "fazer um trabalho" no cemitério! Então muita coisa começou a dar errado na vida dela, e ela jurou que nunca mais ia aparecer em foto. Mas, justamente pela ausência, sua presença fica escancarada nas fotos.

Na casa do lado mora a Kátia, também negra, extremamente discreta - talvez por tudo o que já sofreu de discriminação na própria comunidade por ser mãe de santo. Nunca conversou conosco sobre isso. Várias vezes tentamos entrevistá-la 
e ela sistematicamente se esquivou. No início do ano (2002) sofreu um acidente, a partir do qual sua vida e participação nas atividades comunitárias deu uma guinada importante. Perdendo o emprego, acabou por se engajar na realização das oficinas que vêm acontecendo na comunidade, dispondo-se a ensinar tricô e crochê para um grupo de jovens da comunidade, que já está com uma produção enorme, preparando-se para participar de uma feira de artesanato, a partir da qual seu trabalho passa a ganhar visibilidade na cidade.

Na ponta, na esquina da rua que dá para a Santa Teresinha ${ }^{[10]}$, mora a Celene. Testemunha de Jeová, negra, mostrou-se simplesmente indignada quando, na oportunidade de uma viagem de intercâmbio à Itália, como monitora da Oficina do Saber da comunidade Novo Horizonte ${ }^{[11]}$, Ihe pediram para falar dos cultos afro! Agora ela é aluna do curso de Pedagogia à Distância da UDESC[12]. Natural de São Francisco do sul, foi trazida para cá pelos pais com seis anos, pois o pai, pedreiro, achava que na capital era mais fácil conseguir trabalho. Só que, conta ela, "estava toda vida desempregado". Já a mãe, "vivia grávida". Ela mesma tem uma escadinha, e "só não é um por ano" porque de vez em quando toma coragem e manda embora "o traste do marido" - por quem, aliás, é apaixonada.

Na outra ponta, quase no cotovelo da rua, é a casa da Vanda. Nordestina, sangue quente, garante que "não se mete na vida de ninguém". Mas é encrencada com quase todo mundo por causa das bolas e dos desaforos da meninada!

Em frente à casa da Vanda, na esquina da pracinha, moram a Ivana, o Vento Sul, a Marcela e o Júnior. Não fizeram parte da ocupação. Donos de um carrinho de cachorro-quente, trocaram de ponto e de casa com o morador anterior, o seu Luis do Cachorro-Quente. Passamos um bom tempo sem conseguir saber nada deles, sem conseguir sequer que se dignassem a conversar conosco pelo muro! Só agora - em que a Ivana é uma de nossas maiores amigas e grande apoio de todas as iniciativas da Associação - é que fiquei sabendo que alguns moradores antigos disseram para ela "ter cuidado" com a gente, "porque só queríamos ganhar na política!" Essa descoberta poderia nos assustar, ou surpreender, se todo este tempo de contato já não tivesse nos ajudado a descobrir quão complexas e ambivalentes são essas relações, que em todos os momentos queremos retomar como interculturais.

\section{TENTANDO ENTENDER AS TRILHAS PERCORRIDAS}

Tentativa que não usará forçosamente um traçado linear, uma progressão garantida, mas que antes seguirá os meandros, as descontinuidades de uma realidade, ao mesmo tempo bem viva e em pleno crescimento[13]

Que sentido pode fazer ficar lembrando e contando episódios isolados, fragmentos de histórias que, por falta de tempo e espaço, nem são completas, nem falam a respeito de todos os moradores da comunidade? O sentido principal é esse mesmo: falar de rupturas, exclusões, vidas fragmentadas, em tudo 
diferentes e em tudo similares às nossas próprias. É falar de semelhanças e diferenças entre as impressões que se tem ao olhar a comunidade da Via Expressa e ao chegar a ela, tomando o asfalto novo que contorna o Big.

Recentemente, outr@s professor@s foram conosco até lá, dispost@s a ajudar nos encaminhamentos que a comunidade tem tomado para a reconstrução da casa comunitária. A primeira reação de um deles foi: tudo bem, mas eu não vou lá com o meu carro! Para o bem da verdade vale dizer que isso só aconteceu na primeira vez, antes de ter tido a primeira conversa com a comunidade! Aliás, uma das alunas que participou várias vezes das oficinas, como voluntária, ao comentar que "antes tinha medo até de passar por perto daqui", refletiu: "pensando bem, eles é que deviam ter medo! São eles que estão o tempo todo ameaçados, excluídos, escorraçados..."

Esta pesquisa não se desenvolveu linearmente em "alguns dias que fomos para a comunidade". Ela se entrelaçou e entreteceu, ao longo de dois anos, com outros projetos de ensino, pesquisa e extensão e se insere numa relação de quase dez anos com essa comunidade. Esse percurso tem sido constitutivo de todo o meu fazer profissional e acadêmico. Tenho acompanhado de perto, também, o impacto que este encontro tem provocado em quantos têm participado dos grupos de pesquisa e extensão.

Essa lembrança leva-me de volta a Foucault, quando ele trata da genealogia, como forma de pesquisa. A pesquisa não funda: ela agita o que se percebia como imóvel, ela fragmenta o que se pensava unido; ela mostra a heterogeneidade do que se imaginava em conformidade consigo mesmo (1979, p.21). Cada nova pesquisa volta a agitar o que até há pouco se admitia como certo. Nesse sentido, ela alimenta os processos de ensino, permitindo a emergência de novas questões e novos significados - e abrindo sempre outras perspectivas de busca, não tanto de novas verdades, mas das políticas que constituem os enunciados que podem ser admitidos como verdadeiros - excluindo os demais.

\author{
E agora? \\ É hora de voltar a enrolar os fios de Ariadne...[14] \\ Não haverá nunca uma porta. Estás dentro e o alcácer abarca o \\ universo \\ E não tem nem anverso nem reverso, nem externo muro nem \\ secreto centro.
}

Não esperes que o rigor de teu caminho que teimosamente se bifurca em outro,tenha fim. É de ferro teu destino como teu juiz.

Não aguardes a investida do touro que é um homem e cuja estranha forma plural dá horror à maranha

De interminável pedra entretecida.

Jorge Luiz Borges

Num texto que relata uma pesquisa desenvolvida, espera-se que se sintetizem as 
conclusões a que se chegou. Que novos conhecimentos foram construídos? Que outras perspectivas possivelmente abertas? Que contribuições este trabalho trouxe para o campo disciplinar, ou para o campo teórico em que se insere?

Aí estamos diante do primeiro impasse. Pesquisamos Corpo, Educação Intercultural e Cidadania, numa comunidade de periferia constituída a partir do Movimento Sem Teto. Nosso grupo, orientado por uma educadora, pesquisadora de movimentos sociais, teve a participação de duas formandas (agora formadas) do curso de história e uma militante de movimentos populares, agora aluna do curso de bacharelado em artes plásticas (uma historiadora, agora aluna do mestrado em história, já tinha participado do grupo no primeiro ano de desenvolvimento da pesquisa, como também um formando da geografia). Esse impasse foi também o primeiro grande impulso: por não cabermos dentro de nenhum campo disciplinar específico, tivemos muito menos dificuldade de deixar que a própria pesquisa nos conduzisse por caminhos, como diria Rodrigues (1999, p.12), in-disciplinares. E aprendemos muito nesse percurso.

Nosso objeto de análise era o corpo - e não éramos nem queríamos abordá-lo como profissionais da área da saúde, da educação física ou da moda. Tampouco pretendíamos uma pesquisa totalmente bibliográfica ou meramente empírica. Não era uma pesquisa aplicada - embora também o fosse, já que o envolvimento e o bem-estar da comunidade eram também nossos objetivos. Nosso primeiro passo foi uma garimpagem de textos e obras que se referissem ao corpo - nas diversas bibliotecas a que tínhamos acesso, na internet, nas livrarias. Concomitantemente, fomos para a comunidade. Voltamos a visitar as quarenta e nove famílias, primeiro, para retomar o contato. Depois, para saber de quais das oficinas, pedidas por eles no período anterior, cada um gostaria de estar participando.

A partir daí nosso trabalho só foi possível porque inúmer@s colaborador@s, voluntári@s, juntaram-se a nós: o pessoal das oficinas de cerâmica, da capoeira, da cestaria, do violão; as contadoras de história; sem esquecer daquel@s que garantiram a infra: filmagens, fotografias, o material para as oficinas, os lanches. Gostaríamos de agradecer-lhes de todo o coração, deixando aqui registrado o quanto sua participação foi fundamental para chegarmos - nós e a comunidade onde agora estamos.

A estas alturas, alguém que está nos lendo já pode estar objetando: lanches, oficinas, festa, o que tem isso a ver com pesquisa? E nós poderíamos fazer um discurso bem fundamentado e indiscutivelmente aceito sobre a indissolubilidade dos processos de ensino, pesquisa e extensão, e outras coisas do gênero. Mas preferimos outro caminho, que não nega o anterior, mas lhe reafirma outras perspectivas.

Como Corazza (1996), acreditamos que não é por tal ou qual método que se opta, e sim por uma prática de pesquisa que nos 'toma', no sentido de ser para nós significativa (p.124), sendo sua finalidade primeira a criação de outros modos de existência, como a invenção de novas possibilidades de vida (p.127).

Quando fomos à comunidade para falar-lhes de nossos interesses e objetivos, 
eles também nos manifestaram seus interesses e objetivos: precisavam e queriam se reencontrar, criar novas possibilidades que reinstituíssem o prazer de estar juntos que haviam perdido na caminhada. Queriam, sim, relembrar sua história, mas queriam, principalmente, reconstituí-la, reencontrar-se como comunidade.

Assim nasceram as idéias das festas e das oficinas, que no percurso se tornaram também em reuniões para discutir o IPTU, a prestação dos terrenos e a reorganização da Associação de Moradores, além das incontáveis, muitas horas, mesmo, de conversa para lembrar e ressignificar o trajeto de sem teto a morador, os momentos de ruptura, as centelhas de exercício da cidadania, os dramas e até as tragédias de um cotidiano sempre igual e constantemente diferenciado.

Chegamos aonde queríamos? Diria que fomos além. Chegamos a perscrutar os entre-lugares em que as diferenças se enunciam, mas podem também ser resignificadas. Não apenas constatamos diversidades, como dados ou fatos consumados. Re-criamos, junto com a comunidade, a possibilidade de outros momentos de encontro/confronto, deixando em aberto inúmeras trilhas que ainda mal nos atrevemos a vislumbrar.

E a comunidade, chegou aonde queria? Embora não tenha havido nenhuma mudança estrutural, o clima na comunidade é outro. É como se uma centelha se tivesse reanimado, fazendo-os instituir uma nova disposição para pensar juntos em todas as questões que atravancam o seu dia-a-dia. Muitos deles continuam desempregados, a droga continua seu caminho de tentar se estabelecer na comunidade, os desentendimentos entre marido e mulher, mães e filhos, vizinhos, continuam. Mas o que importa é que as questões voltaram a ser colocadas e eles recomeçaram a ouvir sua própria voz. Então, o que incomodava mas não era explicitado, começou a ser posto para fora. E o grupo voltou a ter propostas. Como afirma um dos integrantes da comunidade: cada um sofre de um lado... Aí a gente se encontra, conversa, festeja junto, conversa... e aparece força para começar tudo de novo.

Em nós se reaviva uma convicção: estamos dentro do Labirinto, irremediavelmente. Labirinto criado pela complexidade de um mundo cada vez mais globalizado e talvez nunca tão fragmentado. Labirinto criado, também, por nossa insistência teimosa em querer pensar e fazer educação sempre colada ao movimento real de uma sociedade composta de pessoas, corpos, de carne, osso, desejos, sentimentos, razão, sentidos, utopias... Quais as conseqüências disso para a educação, particularmente para a formação de educador@s? Em primeiro lugar, a exigência de uma sensibilidade cada vez mais à flor da pele, e um senso crítico cada vez mais aguçado, que continuamente perceba e reconstrua a intrínseca conexão entre teoria e prática. Em seguida, criatividade, maleabilidade, flexibilidade, ao mesmo tempo em que princípios, valores que inspirem as escolhas, que não são mais de cada dia, mas sim de cada instante. $\mathrm{E}$ a percepção de que nenhuma palavra é palavra final (mesmo que sintamos tanta falta das conclusões e dos terrenos seguros!).

\section{BIBLIOGRAFIA}


AZIBEIRO, N. E. Relações de saber, poder e prazer: educação popular e formação de educador@s. Florianópolis: CEPEC, 2002.

BHABHA, H. K. O local da cultura. Trad. de Myriam Ávila, Eliana Lourenço de Lima Reis, Gláucia Renate Gonçalves. Belo Horizonte: Ed. UFMG, 1998.

BORGES, J. L. Elogio da Sombra: poemas, perfis, ensaio autobiográfico. Rio de Janeiro: Globo, s/d.

CORAZZA, S. M. Labirintos da pesquisa, diante dos ferrolhos. In Caminhos Investigativos. Porto Alegre: Mediação, 1996.

COSTA, M. V. Novos olhares na pesquisa em educação. In Caminhos Investigativos. Porto Alegre: Mediação, 1996.

. Elementos para uma crítica das metodologias participativas de pesquisa. In VEIGA-NETO, A.(org.) Crítica pós-estruturalista e educação. Porto Alegre: Sulina, 1995.

DUBY, G. "Advertência", tomo II, In: PROST, Antoine \& VICENT, Gérard. História da Vida Privada, 5: da Primeira Guerra a nossos dias. Trad. Denise Bortmann. São Paulo: Companhia das Letras, 1992.

FOUCAULT, M. Microfísica do Poder. Org. e trad. de Roberto Machado. Rio de Janeiro: Ed. Graal, 1979.

GEERTZ, C. A interpretação das Culturas. RJ: LTC, 1989.

LOBATO, M. O Minotauro. Obras Completas. São Paulo: Brasiliense, s/d.

MACHADO,A. Proverbios y Cantares. Disponível na Internet: <http://www.abelmartin.com>, 1998.

MAFFESOLI, M. No fundo das aparências. Trad. Bertha Halpern Gurovitz. 2ed. Petrópolis, RJ: Vozes, 1996.

MORIN, E. Complexidade e ética da solidariedade. In: Ensaios da Complexidade. Porto Alegre: Ed. Sulina, 1997.

PROST, A. \& VICENT, G. História da Vida Privada, 5: da Primeira Guerra a nossos dias. Trad. Denise Bortmann. São Paulo: Companhia das Letras, 1992.

RODRIGUES, J. C. O Corpo na História. Rio de Janeiro: Editora FIOCRUZ, 1999.

SENNET, R. Carne e Pedra: o corpo e a cidade na civilização ocidental. Trad. Marcos Aarão Reis. RJ: Record, 1997.

\footnotetext{
[1] Georges Duby, na “advertência” do tomo 2 da História da Vida Privada

[2] Adotamos esta forma de grafia seguindo sugestão de pesquisador@s integrantes do Núcleo de Estudos de Gênero - DFH/UFSC, com o intuito de chamar a atenção para nosso padrão lingüístico - sexista, já que adota sempre como correto o masculino plural, mesmo quando é o caso, como na educação ou em comunidades de periferia, em que a maioria é constituída de mulheres.

[3] Costa, 1996, p.13

[4] Caminante, son tus huellas / el camino, y nada más; / caminante, no hay camino, / se hace camino al andar. / $\mathrm{Al}$ andar se hace camino, / y al volver la vista atrás / se ve la senda que nunca / se ha de volver a pisar. /
} 
Caminante, no hay camino, / sino estelas en la mar. Antonio Machado - Proverbios y cantares

[5] O marido da Leda, Nêne, além de beber, não conseguia conviver com a situação em casa: os filhos usavam drogas, e a Leda não conseguia lhes impor limites - ele tampouco, mas "como a responsabilidade de educar os filhos é mesmo da mulher...” Saiu de casa, e a situação ficou ainda mais difícil para a Leda. Os amigos dos filhos começaram a esconder "moamba” (drogas e objetos roubados) no teto de sua casa. Denunciada por vizinhos, ela foi presa e ficou dois anos na Cadeia Pública "por não conseguir controlar os filhos”. Depois de sair da Cadeia não conseguiu continuar na comunidade, trocando sua casa com um Pastor que morava nos arredores. Por sua vez o Cláudio, drogado durante mais de vinte anos, há três anos aceitou submeter-se a um tratamento e desde o ano passado é Presidente da Associação de Moradores e um dos principais articuladores dos projetos que têm-se desenvolvido na comunidade.

[6] Pela relação construída com a comunidade, a extensão é que acaba por se constituir no eixo articulador do ensino e da pesquisa.

[7] Costa, 1996, p. 94.

[8] Maffesoli, 1996, p.41

[9] conjunto residencial da COHAB

[10] Comunidade vizinha, mais antiga, surgida de uma ocupação espontânea no final da década de 1970, reordenada a partir da participação no Movimento Sem Teto.

[11] O projeto Oficinas do Saber trabalha com crianças e adolescentes de 7 a 14 anos, no período em que não estão na escola. Novo Horizonte é outra comunidade da região do Monte Cristo, também organizada a partir do Movimento Sem Teto.

[12] Universidade do Estado de Santa Catarina.

${ }^{[13]}$ Maffesoli, 1996, p.14.

[14] Filha do rei de Creta que se apaixonou por Teseu, herói grego desafiado a vencer o minotauro, fera que dominava o Labirinto. Todos os que haviam entrado no Labirinto, nunca haviam conseguido sair. Ariadne deu, então, a Teseu um fio, para que ele o desenrolasse pelos corredores através dos quais fosse passando, para que, enrolando-o de volta, conseguisse sair. 